Nieuws inzake wetgeving, resoluties en beslissingen op het gebied der belastingen.

\title{
CONSTANTE KOSTEN IN HET KADER VAN DE FISCALE WINSTBEPALING
}

\author{
door D. A. M. Meeles
}

De jaarlijkse fiscale winst moet worden bepaald „,volgens goed koopmansgebruik”. Aan dit wettelijk voorschrift zal men in de regel voldoen indien men aansluit aan hetgeen de bedrijfseconomie omtrent de juiste wijze van winstbepaling leert. Deze regel lijdt echter uitzondering niet alleen ingeval het volgen van het bedrijfseconomisch inzicht strijdig is met de betreffende belastingwet doch ook indien daardoor tekort zou worden gedaan aan de algemene opzet of een beginsel dezer wet. ${ }^{1}$ ) Van strijdigheid met de belastingwet is b.v. sprake bij toepassing van vervangingswaarde-afschrijving, daar de wet slechts afschrijving op basis van de aanschafprijs toestaat. Aan het beginsel der wet wordt b.v. tekort gedaan indien bij de winstbepaling voor enig jaar ten behoeve van de heffing van een belasting, waaraan de jaarlijkse winst ten grondslag ligt, verliezen tot uitdrukking worden gebracht, welke zullen kunnen ontstaan als gevolg van faktoren, welke eerst in een volgend jaar kunnen optreden. ${ }^{2}$ ) Vorming van open of van stille reserves is niet toegestaan, behoudens enkele in de wet genoemde uitzonderingen, die in dit verband niet van betekenis zijn.

Bepalingen of beginselen der wet zullen dus veelal leiden tot een fiscale winstberekening welke naar boven afwijkt van een naar bedrijfseconomische normen vastgestelde winst. Vaak wordt echter voorbijgezien, dat bepalingen of beginselen der wet ook kunnen meebrengen, dat de fiscale winst lager wordt berekend dan die, welke zou voldoen aan bedrijfseconomische normen. Als een beginsel der wet kan men zien de eis, dat door de belastingheffing het voortbestaan der bedrijven niet in gevaar mag worden gebracht. In strijd hiermede zijn het beginsel en de wetsbepalingen, welke reservevorming tegengaan. Gegeven de onmogelijkheid van reservevorming, is de bepaling, dat terugwerkende verliescompensatie slechts voor één jaar mogelijk is, evenzeer in strijd met het beginsel, dat de fiscus de kip met de gouden eieren niet naar het leven moet staan. Ten slotte zijn de wetsbepalingen, welke de fiscus toestaan reeds in de loop van het boekjaar door middel van voorlopige aanslagen zijn doorgaans niet geringe aandeel in de jaarwinst in contanten op te eisen, in strijd met het bedrijfseconomisch beginsel dat de winstbepaling aan de winstbestemming vooraf behoort te gaan. Dit alles leidt tot de conclusie, dat het - eenvoudigweg uit een oogpunt van lijfsbehoud - noodzakelijk kan zijn bij de fiscale winstbepaling veel voorzichtiger te werk gaan dan bij een bedrijfseconomische winstvaststelling. Met name zal men aan de realisatiegedachte bij de fiscale winstbepaling een veel grotere plaats dienen te geven dan doorgaans bij een bedrijfseconomische winstbepaling geschiedt. ${ }^{3}$ ) Het is dan ook toe te juichen, dat in de jurisprudentie van de Hoge Raad het realisatiebeginsel, zij het in beperkte mate, voor de fiscale winstbepaling is aanvaard. Naast de in deze be-

\footnotetext{
1) Arrest van 8 mei 1957, B.N.B. 1957/208.

2) Arrest van 2 oktober 1957, B.N.B. 1957/300.

3) Zie ook de desbetreffende beschouwingen van mijn mederedacteur Wisselink op blz. 302 van het julinummer 1958 van dit Maandblad.
} 
schouwing te bespreken arresten wijs ik in dit verband op de gedachtengang, welke o.m. ten grondslag ligt aan het wijnvoorraadarrest ${ }^{4}$ ), aan de ruilarresten en aan de z.g. huurkooparresten. Naar mijn oordeel verdient deze gedachtengang bij de fiscale winstbepaling een veel ruimere toepassing, dan men vrij algemeen voor mogelijk houdt.

Uit het vorenstaande vloeit voort, dat ik geenszins het scepticisme deel, dat in bedrijfseconomische kringen kon worden beluisterd naar anleiding van het eerste z.g. ",vaste-kostenarrest" van de Hoge Raad. ${ }^{3}$ ) Juist de vaste kosten bewerken, dat men in jaren van teruglopende omzet grote verliezen kan lijden, waarvoor de wet, die de daarvoor geëigende reservevorming niet toestaat en bovendien niet cen bij gebreke van reservevorming noodzakelijke meerdere jaren terugwerkende verliescompensatie kent, geen enkel soelaas biedt.

Het vaste-kostenarrest van 30 mei $1956^{\circ}$ ) werd nog gewezen voor een belastingjaar, waarop de vóór 1950 geldende wetgeving van toepassing was. Bij de fiscale winstbepaling werd destijds uitgegaan van het systeem van de vermogensvergelijking. Voorgeschreven was, dat de activa van de vermogensbepalende balans moesten worden gewaardeerd volgens goed koopmansgebruik, doch tenminste op de werkelijke aanschaffings- of voortbrengingskosten. De Hoge Raad oordeelde, dat onder deze kosten slechts vielen die uitgaven, welke bepaaldelijk door de vervaardiging van de geproduceerde goederen zijn opgeroepen. Niet behoort hiertoe het constante deel van de algemene bedrijfskosten daar, zolang het bedrijf op de bestaande voet wordt in stand gehouden, deze kosten onafhankelijk van de omvang der produktie moeten worden uitgegeven. Sinds dit arrest werd gewezen is er een principiële strijd ontstaan omtrent de werkingssfeer daarvan, welke strijd thans met het arrest van de Hoge Raad van 21 juni 1961 rolnr. 14459 wel definitief ten gunste van de belastingplichtigen is beëindigd.

De belastingadministratie heeft zich van de aanvang af op het standpunt gesteld, dat het vaste-kostenarrest slechts betekenis kon hebben voor op voorraad werkende produktiebedrijven. De Hoge Raad had immers overwogen, dat ,activering in den voorraad van de constante aan den algemenen opzet van het bedrijf verbonden kosten achterwege mag blijven, omdat de koopman zich op het standpunt kan en dus mag stellen, dat deze kosten niet naar gelang van het vorderen van de productie, maar naar gelang van het vorderen van den verkoop worden terugverdiend". Zo er op de balansdatum een verkoopovereenkomst is, zo oordeelde men, moeten dus de daarop betrekking hebbende nog niet afgeleverde voorraden integraal en niet differentieel worden gewaardeerd. Ergo zou het vaste-kostenarrest in het geheel geen betekenis kunnen hebben voor op bestelling werkende bedrijven en met name dus ook niet voor bedrijven, die zich bezig houden met aanneming van werken.

Met deze interpretatie bleek echter het arrest van 30 mei 1956 te zijn misverstaan. In 1959 kreeg de Hoge Raad gelegenheid zich hieromtrent uit te laten. ${ }^{7}$ ) Overwogen werd, dat ten aanzien van de voorraden fabrikaten en halffabrikaten van een textielfabriek, ,goed koopmansgebruik toelaat de vaste, van den omvang

4) Arrest van 17 februari 1954, B.N.B. 1955/138.

5) Zie o.m. de naar aanleiding van genoemd arrest in de jaargang 1957 van dit tijdschrift verschenen artikelen van N. D. de Ridder (mei 1957) en A. J. A. van der Heide (september 1957).

B) B.N.B. 1956/222.

7) Arrest van 17 juni 1959, B.N.B. 1959/304. 
der productie in beginsel onafhankelijke, kosten in de waardering der producten niet tot uitdrukking te brengen, doch die kosten te laten drukken op de periode, waarin zij zijn gemaakt en deze mitsdien eerst als terugverdiend te beschouwen naar mate die producten worden gerealiseerd;

dat, aangezien van realisatie niet reeds behoeft te worden gesproken, wanneer de goederen zijn besteld of verkocht, doch eerst, wanneer zij door levering aan den voorraad zijn onttrokken en de koopprijs is ontvangen of als vordering in de boeken wordt opgenomen, geen aanleiding bestaat de blijkens het bovenstaande ten aanzien van de behandeling van het constante deel der algemene kosten in het algemeen bestaande vrijheid uit te sluiten, indien de voorraad voor een gedeelte uit reeds verkochte goederen bestaat."

Nog was hiermede de zaak niet beslecht omdat, mede in verband met oudere jurisprudentie, de vraag bleef bestaan of de hier vermelde, voor de voorraden fabrikaten en halffabrikaten van een fabrieksbedrijf gegeven beslissing zonder meer ook op onderhanden werken van een aannemingsbedrijf van toepassing zou kunnen zijn. De kwestie werd dan ook ten derde male in een procedure aanhangig gemaakt. Het Gerechtshof analyseerde de verschillen tussen een fabrieksbedrijf en een aannemingsbedrijf en kwam op grond daarvan tot de conclusie dat deze verschillen geen af wijkende fiscale behandeling van de aannemingsbedrijven rechtvaardigden. Ook het punt, dat het onderhanden werk van een aannemer doorgaans in veel belangrijker mate met afnemerskrediet wordt gefinancierd dan de voorraad (half)-fabrikaat van een fabrikant, hetgeen het financiële risico beperkt, vormde voor een afwijkende behandeling niet voldoende motief. De overwegingen waarmede de Hoge Raad het oordeel van het Hof bevestigde luidden als volgt:

„dat de constante algemene kosten zich van de overige algemene kosten en van de bijzondere kosten onderscheiden, doordat de beide laatstgenoemde door de produktie bepaaldelijk worden opgeroepen, dat wil zeggen daarvoor in ieder geval nodig zijn en daarmede onmiddellijk samenhangen, terwijl de eerste, zolang het bedrijf op den bestaanden voet wordt voortgezet, in beginsel onafhankelijk van het wisselend verloop van de produktie worden gemaakt;

dat niet on redelijk, immers met een voorzichtig beleid in overeenstemming, is en derhalve als goed koopmansgebruik moet worden aangemerkt bij de waardering naar kostprijs van hetgeen in het bedrijf werd geproduceerd en nog niet afgeleverd is uit te gaan van de gedachte, dat in de waarde van het geproduceerde in het algemeen wèl de daarin verwerkte min of meer duidelijk aanwijsbare kosten, welke een ieder zou moeten maken, worden teruggevonden, nièt echter de constante algemene kosten welke veelal van bedrijf tor bedrijf zullen verschillen en welke, evenals een winstopslag, eerst bij volledige af werking en levering zullen worden gerealiseerd;

dat het in de eerste alinea bedoelde verschijnsel zich evenzeer kan voordoen in een bedrijf dat is gericht op het aannemen van werk, vermits ook in een zodanig bedrijf een gedeelte van de algemene kosten zich hierdoor kenmerkt, dat het - in den regel naar tijdsgelang - moet worden besteed onafhankelijk van het wisselend verloop van de bedrijfsbezctting, en in zulk een bedrijf vooral van betekenis is indien werken worden aangenomen, waarvan de uitvoering zich over een langdurig tijdsverloop uitstrekt;

m a b blz. 429 
dat derhalve ook in een zodanig aannemersbedrijf reden is bij de jaarlijkse winstberekening de constante algemene kosten buiten aanmerking te laten bij de waardering van aangenomen werken die aan het einde van het boekjaar in meer of minder gevorderden staat van uitvoering zijn, ook al moge bij de prijscalculatie voor elk werk, naast de kosten der voor de uitvoering van het werk vereiste materialen en de daaraan te besteden arbeidslonen en andere variabele kosten, een naar bedrijfseconomische inzichten bepaalde bijdrage in het constante deel der algemene kosten worden begrepen;

dat in den gedachtengang waarop het door belanghebbende voorgestane stelsel van berekening der fiscale winst berust, het niet in de waardering begrijpen van een bijdrage in het constante deel der algemene kosten niet, zoals in de toelichting tot het middel wordt betoogd, de betekenis heeft van het tot uitdrukking brengen van een - niet geleden - verlies en evenmin in strijd is met enige bijzondere bepaling of met den algemenen opzet van het Besluit".

Uit dit arrest zijn, mede in verband met vroegere jurisprudentie, thans de volgende conclusies te trekken:

1. De eliminering van de constante kosten bij de waardering naar kostprijs van op de balansdatum nog niet af- of opgeleverd produkt is voor geen enkele bedrijfstak uitgesloten;

2. Het arrest van 21 juni 1961 vormt voor aannemingsbedrijven een bijzondere omstandigheid, welke het mogelijk maakt alsnog tot de door de Hoge Raad aanvaarde gedragslijn te besluiten. ${ }^{8}$ ) In beginsel zal deze mogelijkheid dienen te worden benut met ingang van het eerste boekjaar, waaromtrent ten tijde van het bekendworden van het arrest nog een beslissing moet worden genomen, tenzij, als gevolg daarvan zou moeten worden teruggekomen op reeds gedane aangiften en zulks tot dergelijke moeilijkheden zou leiden, dat dit in redelijkheid niet kan worden gevergd; alsdan kan ook een later boekjaar als jaar van ingang worden gekozen. ${ }^{9}$ )

Tezelfdertijd kreeg de Hoge Raad gelegenheid zich uit te spreken over de praktische vraag welke inhoud in het kader van de fiscale winstbepaling aan het begrip constante kosten dient te worden gegeven. Het betreft hier de arresten van 21 juni 1961 rolnummer 14483 en van 4 juli 1961 rolnummer 14322.

In de procedure, welke leidde tot het eerstgenoemde arrest, had het Gerechtshof o.m. tot de constante kosten gerekend de afschrijving en onderhoudskosten van gebouwen, de grond- en straatbelasting, de kosten in verband met assurantie van de bedrijfsapparatuur, de salarissen hoofdpersoneel, de indirecte lonen en de sociale lasten daarop, de kosten van verwarming en verlichting, alsmede de accountantskosten. Echter was het Hof van oordeel dat de afschrijvingen op en onderhoudskosten van de bedrijfsmiddelen, die rechtstreeks aan de produktie dienstbaar zijn, zijnde de machines en de gereedschappen, in de fiscale balanswaardering van halffabrikaat en gereed produkt tot uitdrukking zouden moeten komen. Het standpunt van belastingplichtige kwam, kort omschreven, hierop neer: de (fiscale) afschrijving op machines en gereedschappen wordt uitsluitend

8) Dit vloeit voort uit het arrest van de Hoge Raad van 8-1-1958 B.N.B. 1958/58.

9) Aldus het arrest van de Hoge Raad van 22-6-1960 B.N.B. 1960/254.

m a b blz. 430 
bepaald door drie elementen: historische kostprijs, geschatte levensduur en restwaarde van het bedrijfsmiddel. De afschrijving is dus onafhankelijk van de omvang van de produktie. Zouden de op de balansdatum aanwezige voorraden produkt en halffabrikaat niet zijn vervaardigd, dan zou dus hetzelfde bedrag aan afschrijving op machines en gereedschappen ten laste van de resultatenrekening zijn gebracht als thans. Ergo behoort de genoemde afschrijving niet tot de door de vervaardiging van de balansvoorraden bepaaldelijk opgeroepen kosten, zodat het niet nodig is om een gedeelte van deze afschrijving door middel van toerekening aan de op de winstbepalende balans paraisserende voorraden naar de winstberekening van een volgend jaar door te schuiven.

Deze juridische benadering kon op grond van de volgende overwegingen in de ogen van de Hoge Raad geen genade vinden:

„dat weliswaar het aanschaffen van machines en gereedschappen uitgaven vereist, welke leiden tot regelmatige afschrijvingen op de aanschaffingskosten, maar zulks onverlet laat, dat machines en gereedschappen, die in het bedrijf worden gebezigd voor de vervaardiging van de produkten, bestanddelen vormen van het bedrijfsvermogen, waarvan de waarde van lieverlede in de vorm van arbeidsvermogen rechtstreeks aan de produkten wordt afgestaan om als resultaat hiervan in de waarde van het gerede produkt te worden teruggevonden;

dat daarom de waarde van voltooide en onvoltooide produkten in voorraad niet alleen wordt ontleend aan de grond- en hulpstoffen die daarin zijn verwerkt en de menselijke arbeidskracht welke daaraan is besteed, maar evenzeer aan het machinale arbeidsvermogen dat daartoe is verbruikt;

dat bovendien niet alleen voor machines en gereedschappen geldt, dat de nutsprestaties welke zij in staat zijn te leveren, ineens moeten worden aangeschaft en eerst geleidelijk worden verbruikt, daar dit verschijnsel zich naar de aard van een bedrijf evenzeer kan voordoen ten aanzien van gronden hulpstoffen die in de produkten worden verwerkt, terwijl veelal evenmin de sterkte van het personeel, ook voor zover het uitsluitend en rechtstreeks voor de produktie werkzaam is, door het wisselend verloop van de omvang der produktie wordt bepaald;

dat het Hof mitsdien terecht heeft geoordeeld, dat goed koopmansgebruik vereist bij de waardering van fabrikaten en halffabrikaten in voorraad rekening te houden met nutsprestaties of werkeenheden, afkomstig van machines en gereedschappen die rechtstreeks aan de produktie dienstbaar zijn, zodat ook het subsidiair voorgestelde middel faalt".

De motivering, welke de Hoge Raad tot zijn conclusie voert, zal voor velen niet overtuigend klinken.

Met betrekking tot de overweging, dat de waarde van de voorraad produkt o.m. wordt ontleend aan het verbruikte machinale arbeidsvermogen zou men zich n.l. kunnen afvragen of deze waarde niet mede wordt ontleend aan het constante deel der opgeofferde algemene kosten waarvoor aktivering wèl achterwege kan blijven. Bovendien is het de - economische - vraag, of de waarde niet eerder door de marktverhoudingen wordt bepaald dan door de - in casu historische - kostprijs van de technisch in het produkt opgegane produktiefaktoren.

Blijkens de eerste en derde overweging onderkent de Hoge Raad punten van 
overeenstemming tussen de z.g. directe kosten (grond- en hulpstoffen en directe lonen) en de kosten, veroorzaakt door het gebruik van de zogenoemde directe produktiemiddelen, waaronder zijn te verstaan produktiemiddelen, welke rechtstreeks arbeidsvermogen aan de produkten afstaan. Uit de derde overweging zou men als mening van de Hoge Raad kunnen afleiden, dat de machinekosten zich niet wezenlijk van de kosten voor grondstoffen en lonen onderscheiden. Het vermeende onderscheidende kenmerk van de gedwongen voorraadvorming zal zich veelal ook ten aanzien van laatstgenoemde produktiefaktoren voordoen. Evenwel is de voorraadvorming in grondstoffen en directe arbeid doorgaans zodanig wezenlijk verschillend van die in werkeenheden van duurzame produktiemiddelen, dat men aan het feit van de voorraadvorming zelve m.i. geen conclusie mag verbinden met betrekking tot de kostentoerekening. Belangrijke verschillen zijn o.m. de veel grotere tijdsduur waarover de voorraadvorming in werkeenheden van duurzame produktiemiddelen zich uitstrekt, de inelasticiteit in de aanwendingsmogelijkheid der werkeenheden (men kan de voorraad werkeenheden niet sneller opgebruiken dan de gelijktijdige capaciteit van de betreffende produktiemiddelen toestaat), de ondeelbaarheid, waardoor men na de aanschaffing blijkende overschotten niet tijdig kan afstoten, het doorgaans ontbreken van alternatieve aanwendingsmogelijkheden e.d. De omstandigheid, dat men in de duurzame produktiemiddelen doorgaans een voor vele jaren toereikende hoeveelheid werkeenheden aanschaft, zodat men in aanzienlijk ruimere mate dan ten aanzien van de produktiefaktoren grondstof en arbeid vooruit moet lopen op de toekomst, bewerkt, dat deze produktiemiddelen eerder te vergelijken zijn met leidinggevende en toezichthoudende arbeid, dan met de rechtstreeks voor de produktie werkzame arbeid, welke zoal niet onmiddellijk, dan toch binnen een betrekkelijk kort tijdsbestek aan de omvang van de produktie kan worden aangepast.

Dat de Hoge Raad niet tot een voor ieder bevredigende motivering is gekomen is toe te schrijven aan de omstandigheid, dat zijn overwegingen zijn gebaseerd op een technische beschouwingswijze. Eerder had men mogen verwachten, nu de Hoge Raad een juridische benadering van het juridisch/bedrijfseconomische probleem van de fiscale kostentoerekening verwerpt, dat een bedrijfseconomische benadering van het vraagstuk zou zijn gekozen. Daarbij had dan aan de orde kunnen komen dat afschrijving tot uitdrukking brengt de slijtage der duurzame produktiemiddelen. Deze slijtage wordt bepaald:

a. door het verstrijken van de tijd;

hieronder valt de slijtage als gevolg van de z.g. economische veroudering, alsmede de technische slijtage door de tijd (corrosie, o.m. door chemische en atmosferische invloeden);

b. door de mate waarin het produktiemiddel technisch wordt gebruikt.

Indien de slijtage uitsluitend wordt bepaald door het gebruik zijn de kosten van afschrijving, die dan ook niet naar tijdsgelang doch naar de mate van gebruik moeten worden berekend, bedrijfseconomisch te rekenen tot de variabele kosten. Indien de slijtage uitsluitend wordt bepaald door het verstrijken van de tijd moeten de afschrijvingskosten worden gerekend tot de constante kosten. Indien een produktiemiddel zowel is onderworpen aan technische en/of economische slijtage door het verstrijken van de tijd als aan technische slijtage door gebruik, doch laatst- 
genoemde slijtage werkt als gevolg van intensief gebruik sneller dan de slijtage door eerdergenoemde faktoren, dan behoort slechts dat deel van de afschrijving tot de variabele kosten, dat overtreft een afschrijving welke op basis van slijtage door het verstrijken van de tijd zou zijn berekend.

Op deze wijze zou m.i. een beter hanteerbaar criterium zijn verkregen dan dat, hetwelk de Hoge Raad thans heeft gekozen. Vooreerst zou een bedrijfseconomisch criterium op alle duurzame produktiemiddelen van toepassing zijn geweest en niet alleen op de z.g. directe produktiemiddelen, een thans door de jurisprudentie gecreëerd fiscaal-technisch begrip, zonder bedrijfseconomische inhoud. De vraag, welke produktiemiddelen tot deze directe produktiemiddelen behoren, zal voor vele fabricageprocessen nog tot de nodige geschilpunten aanleiding kunnen geven. Ingeval van een bedrijfseconomische benadering zou voorts in de meeste gevallen voor de fiscale winstbepaling kunnen zijn aangesloten bij de doorgaans in de bedrijfsadministratie aanwezige splitsing tussen constante en variabele kosten. Ten slotte zou men dan ook het vraagstuk hebben kunnen ontgaan hoe een op slijtage door het verstrijken van de tijd gerichte afschrijving aan de eenheden produkt moet worden toegerekend.

Omtrent laatstgenoemd vraagstuk komen de volgende overwegingen voor in het arrest van 4 juli 1961, rolnummer 14322:

,dat het in het huidige tijdsgewricht geen regel doch slechts uitzondering is, dat de waardevermindering van produktiemiddelen gedurende het produktieproces niet wordt opgewogen door het nut, dat zij voor de produktie af werpen en dat in de waarde van het produkt wordt teruggevonden;

dat in het onderhavige geval zich een uitzondering als bedoeld stellig niet heeft voorgedaan, daar toch blijkens 's Hofs feitelijke vaststelling de in een afschrijving van $20 \%$ van de aanschaffingskosten uitgedrukte waardevermindering van de directe produktiemiddelen haar grond vond in hun technische slijtage, het bedrijf bezet was overeenkomstig zijn capaciteit en van overcapaciteit van de produktiemiddelen niet is gebleken, terwijl de hoogte van de toegepaste afschrijving wees op een snel verbruik van deze produktiemiddelen".

Indien het bedrijf volbezet is, zodat geen onderbezettingsverliezen optreden, behoort dus naar het oordeel van de Hoge Raad het volle bedrag der afschrijvingen over de geproduceerde goederen te worden omgeslagen. A contrario volgt hieruit, dat onderbezettingsverliezen niet behoeven te worden ingecalculeerd. Niet is beslist hoe moet worden gehandeld ten aanzien van de z.g. vervroegde afschrijving. Het lijkt rationeel laatstgenoemde afschrijving, althans voorzover deze „vervroegd" is, voor de kostentoerekening buiten beschouwing te laten.

De hier vermelde overwegingen van de Hoge Raad moeten niet worden gezien als een argument voor de stelling, dat de afschrijving op de z.g. directe produktiemiddelen tot de variabele produktiekosten moet worden gerekend. In het huidige tijdsgewricht worden n.l. doorgaans ook de niet voor verplichte toerekening in aanmerking komende constante kosten bij volledige bezetting in de waarde van het produkt teruggevonden. Trouwens, ware dat niet zo, dan bestond er geen toerekeningsprobleem, omdat dan de niet in de waarde van het produkt goedgemaakte kosten reeds uit een oogpunt van goed koopmansgebruik buiten beschouwing zouden kunnen blijven. 
Uit de besproken arresten kunnen de volgende conclusies worden getrokken op het punt van de splitsing tussen constante en variabele kosten ten behoeve van de waardering in de fiscale winstbepalende balans van onderhanden werk en gereed produkt:

1. Tot de niet in de waardering te begrijpen constante kosten behoren o.m. de kosten van de leiding, de huisvestingskosten, de toezichthoudende arbeid en de administratiekosten. Voorts behoren daartoe afschrijving en onderhoud van niet rechtstreeks voor de produktie gebezigde duurzame produktiemiddelen.

2. Afschrijving en onderhoud van machines en gereedschappen, welke rechtstreeks voor de vervaardiging van het produkt worden gebezigd, kunnen bij de fiscale balanswaardering niet buiten beschouwing blijven.

3. De afschrijving, voorzoveel niet vervroegd, behoeft alleen dan ten volle aan de produktie te worden toegerekend, indien er sprake was van volledige (normale) bezetting; door onderbezetting teloorgegane werkeenheden kunnen ook fiscaal direct als verlies worden beschouwd. 